DEUİFD Türk Kültürünü Mayalayanlar Özel Sayısı / 2021, ss. 629-640.

\title{
İLAHİYAT EĞİTİMİNDE HACI BEKTAŞ VELİ: İLAHİYAT FAKÜLTESİ ÖĞRENCİLERİNİN HACI BEKTAŞ VELİ İLE İLGİLİ BİLGİ, ALGI VE KARŞILAŞMA ALANLARI*
}

Mustafa Fatih AY**

\section{ÖZ}

Bu çalışmanın temel amacı İlahiyat Fakültesi öğrencilerinin Hacı Bektaş Veli ile ilgili bilgi, algı ve karşılaşma alanlarını belirlemektir. Bu amaç çerçevesinde hem müfredat hem de müfredatın sahada uygulanışının ele alınabilmesi için çalışmanın yöntemi, karma yöntem araştırma desenlerinden paralel yakınsayan desen olarak seçilmiştir. Çalışma sonucunda katılımcıların büyük çoğunluğunun $(\% 96,3)$ Hacı Bektaş Veli hakkında çeşitli düzeylerde bilgi sahibi olduğu ve bilgilerinin kaynağının ise büyük oranda $(\% 67,4)$ okul merkezli (lise ve ilahiyat) olduğu tespit edilmiştir. Ders içerikleri incelendiğinde elde edilen bulgular ile sahadan elde edilen bulgular arasında bir uyum olduğu görülmektedir. Zira, ders içeriklerinde en çok Tasavvuf vb. derslerde yer alan Hacı Bektaş Veli, öğrenciler tarafından da en çok bu dersler aracılığıyla öğrenilmektedir.

Anahtar Kelimeler: İlahiyat Eğitimi, İlahiyat Eğitiminde Hacı Bektas Veli, Hacı Bektass Veli Algusı, Ilabiyat Fakültesi Öğrencileri.

\footnotetext{
Yazar; çalışmanın hazırlanması esnasında bilimsel ve etik ilkelere uyulduğunu ve yararlanılan tüm kaynakların kaynakçada belirtildiğini, çalışmanın maddi açıdan fonlanmadığını, çıkar çatışması bulunmadığını beyan etmektedir

** Dr. Öğr. Üyesi, Akdeniz Üniversitesi İlahiyat Fakültesi, E-Posta: mustafafatihay@gmail.com, ORCID ID: https://orcid.org //0000-0003-0433318X

Makalenin Hakemlere Gönderiliş Tarihi : 06/12/2021

Makalenin Hakemlerden Geliş Tarihi : 14/12/2021
} 


\title{
HAJI BEKTASH VELI IN THEOLOGY EDUCATION: FACULTY OF THEOLOGY FACULTY STUDENTS' OF KNOWLEDGE, PERCEPTION AND ENCOUNTER AREAS WITH HAJI BEKTASH VELI
}

\begin{abstract}
The main purpose of this study is to determine the knowledge, perception, and encounter areas of the students of the Theology Faculty about Haci Bektash Veli. Within the framework of this purpose, the method of the study was chosen as a parallel convergent design from the mixed method research designs in order to handle both the curriculum and its implementation in the field. As a result of the study, it was determined that the majority of the participants $(96.3 \%)$ had various levels of knowledge about Haci Bektash Veli, and the source of their knowledge was largely (67.4\%) school-centered (high school and theology faculty). When the course contents are examined, it is seen that there is a harmony between the findings obtained from the field and the findings obtained from the field. Because most of the course content is Sufism and so on. Haci Bektash Veli, who takes part in the courses, is mostly learned by the students through these courses.
\end{abstract}

Keywords: Theology Education, Haci Bektash Veli in Theology Education, Perception of Haci Bektash Veli, Faculty of Theology Students.

\section{GİRİŞ}

Hacı Bektaş Veli, Anadolu olarak ifade edilen coğrafyanın barış, kardeşlik, birlik, hoşgörü gibi erdemlerinin oluşmasında önemli rol oynayan abide şahsiyetlerden biridir. Bu nedenle farklı yönleri ile farklı alanlarda çalışmalara konu edilen Hacı Bektaş Veli, günümüzde ise daha çok Alevilik-Bektaşilik tartışmaları ile gündeme gelmektedir. Bu kapsamdaki tartışmaların yapıldığı alanlardan biri de din eğitimidir. Din eğitimi içerisinde Hacı Bektaş Veli, okullarda zorunlu olarak okutulmakta olan Din Kültürü ve Ahlak Bilgisi (DKAB) dersleri kapsamında Aleviliğin yer alması ile ilgili tartışmalarda gündeme gelmektedir.

Diğer yandan ülkemizde din hizmetleri faaliyetlerini yürüten ve organize eden kurum olarak Diyanet İşleri Başkanlığı'nın tüm toplum kesimlerine yönelik din hizmetinde bulunduğu bir gerçektir. Bu çerçevede DKAB Öğretmenliği ve Din Hizmetleri olarak her iki hizmet alanının da ihtiyacı olan personeli yetiştiren ilahiyat fakültelerinde verilmekte olan eğitim içerisinde Hacı Bektaş Veli'nin yerinin 
incelenmeye değer olduğu düşünülmektedir. $\mathrm{Bu}$ nedenle çalışmanın birinci temel hareket noktası genelde din eğitimi alanı özelde ise ilahiyat eğitimi içerisindeki bir öğrencinin Hacı Bektaş Veli ile ilgili bilgi, alg1 ve karşılaşma alanlarını tespit etmektir. Bu çerçevede ilk olarak ilahiyat fakültesi ders içeriklerinde Hacı Bektaş Veli’ye yer verilip verilmediği incelenmiştir. Ayrıca İlahiyat Fakültesi öğrencilerinin, ilahiyat eğitimi sürecinde Hacı Bektaş Veli ile karşılaşma alanları belirlenmeye çalışılarak teori ile pratik arasındaki ilişki de karşılaştırılmışır.

Çalışmanın ikinci hareket noktası olarak ise Hacı Bektaş Veli hakkında bilgi ve algıların konu edildiği çalışmalar incelendiğinde İlahiyat Fakültesi öğrencilerinin konu edildiği bir çalışmaya rastlanılmamış olmasıdır. İlgili literatürde farklı örneklemlerde yapılan çalışmalar olduğu, örneklemleri incelendiğinde, öğretmen adaylarının (Yazıc1, 2014, 109), Nevşehir Hacı Bektaş Veli Üniversitesi [NHBVÜ] ve Kırşehir Ahi Evran Üniversitesi [KAEÜ] öğrencilerinin (Şahïn, 2014, 180-181), farklı bölümlerde öğrenim gören üniversite öğrencilerinin (Ç̈̈fci, 2011, 225; Okur, 2012, 199) olduğu görülürken bir çalışmada ise Türk toplumunda Hacı Bektaş Veli algısı ele alınmıştır (Işı1k vd., 2010, 179, 181). Çalışmalar bir bütün olarak incelediğinde farklı örneklemlerde Hacı Bektaş Veli algısının araştırıldığı görülmektedir. Ancak yapılan çalışmalarda algıların örnekleme özgü yapısının ele alınmadığı bir başka deyişle örneklemde algının nasıl meydana geldiği, kaynakları ve nedenlerine ilişkin bir inceleme yapılmadığ1 görülmektedir. Bu nedenle bu çalışma ile İlahiyat Fakülteleri'nde verilen eğitimde Hacı Bektaş Veli'nin yeri ve İlahiyat Fakültesi öğrencilerinin Hacı Bektaş Veli ile ilgili bilgi düzeyleri, algıları ve Hacı Bektaş Veli ile ne zaman ve nasıl karşılaştıklarının belirlenmesi amaçlanmıştır.

\section{YÖNTEM}

$\mathrm{Bu}$ çalışmada karma yöntem araştırma desenlerinden paralel yakınsayan desen kullanılmıştır. Yakınsayan paralel desen araştırma sürecinin aynı aşamasında hem nitel hem de nicel verilerin toplanıp ayrı ayr1 analiz edilmesinden sonra, elde edilen sonuçların birbirini tamamlayıcı şekilde sentezlenmesi veya karşılaştırılmasıdır (Creswell Plano Clark, 2015, 84). Nitel Boyut: Bu boyutta Akdeniz Üniversitesi İlahiyat Fakültesi müfredatı ("Müfredat Dersleri", 13 Kasım 2021) zorunlu ve seçmeli derslerin tamamını kapsayacak şekilde incelenmiştir. Her bir dersin 14 haftalık içeriği tek tek incelenmiştir. İnceleme kriteri 
olarak da Hacı Bektaş Veli, Bektaşilik, Bektaşiyye gibi kavramlar merkeze alınmıştır. Nicel Boyut: Bu boyutta verilerin toplanması için anket tekniği kullanılmıştır. Anket formu Akdeniz Üniversitesi Sosyal ve Beşeri Bilimler Bilimsel Araştırma ve Yayın Etiği Kurulu'nun 04 Ağustos 2021 tarihli toplantısından alınan 09/288 numaralı karar ile toplanmıştır. Çalışmanın örneklemi uygun örnekleme olarak belirlenmiştir. Verilerin analizinde ise betimsel analizler kullanılmıştır.

\section{Katılımcılara İlişkin Demografik Bilgiler}

Araştırmaya 56'sı erkek, 134'ü kız olmak üzere toplam 190 öğrenci katılmıştır. Katılımcıların sınıflara göre dağılımı ise 1. Sınıf:19, 2. Sınıf:38, 3. Sınıf:73, 4. Sınıf:60 öğrenci şeklindedir. Katılımcılardan 121’i İmam Hatip Lisesi, 50'si Anadolu Lisesi, 19'u ise diğer lise türlerinden mezundur. Katılımcıların mezun olduğunda yapmak istediği mesleklere göre dağ̣llım ise, 114 kişi öğretmen, 47 kişi akademisyen, 25 kişi din görevlisi, 4 kişi ise diğer meslekler şeklindedir.

\section{BULGULAR}

\section{1. İlahiyat Eğitiminde (Lisans Programında) Hacı Bektaş Veli}

Çalışmanın alan araştırmasının örneklemi Akdeniz Üniversitesi İlahiyat Fakültesi öğrencileri olduğundan dolayı, sahadan gelen verilerin teori ile (lisans programı) karşılaştırılabilmesi için bu çalışmada Akdeniz Üniversitesi İlahiyat Fakültesi lisans programı ve ders içerikleri incelenmiştir.

Lisans programı detaylı olarak incelendiğinde Hacı Bektaş Veli ile ilgili içeriğin olduğu iki zorunlu (her öğrencinin alması gerekli olan ders) dersten biri İslami Türk Edebiyatı dersidir. Haftada 2 saat, teorik olarak planlanan bu ders 2.Sınıf 4. Yarıyılda yer almaktadır. Dersin içeriği incelendiğinde ise 6. Hafta içeriğinin Hacı Bektâş̧-1 Velî ve Türk Kültürüne Etkileri şeklinde olduğu görülmektedir. Diğeri ise Tasavvuf II dersidir. Haftada 2 saat, teorik olarak planlanan bu ders 3.Sinif 6 . Yarıyılda yer almaktadır. Dersin içeriği incelendiğinde ise 5. Hafta içeriğinin Bayramiyye, Bedeviyye, Bektaşiyye, Çiştiyye şeklinde olduğu görülmektedir ("Müfredat Dersleri”, 13 Kasım 2021). Bektaşiyye şeklinde yer verilen Bektaşilik ile ilgili konu içerisinde öğrencilerin Hacı Bektaş Veli ile karşılaşmaları muhtemeldir. Bir başka deyişle 2. Sınıf 4. Yarıyılı ve 
3. Sınıf 6. Yarıyılı başarı ile tamamlayan bir öğrencinin Hacı Bektaş Veli hakkında bilgi sahibi olması beklenmektedir.

Hacı Bektaş Veli’nin ders içeriğinde yer bulduğu diğer dersler ise seçmeli derslerdir. Bu derslerden 3.Sınıf 5.Yarıyılda yer alan Tasavvuf Düşünürleri (2 saat, teorik) dersi içeriğinin 4. haftasında Hacı Bektaş-1 Veli ve Düşüncesi şeklinde, 3.Sınıf 5.Yarıyılda yer alan İslam Mezhepleri Tarihi Klasik Kaynakları (2 saat, teorik) dersi içeriğinin 7 ve 14 . Haftalar arasında Bektaşilik'in detaylı bir şekilde ele alınmasının planlandığ 1 görülmektedir. 3.Sınıf 6.Yarıyılda yer alan Türk Düşünce Tarihi (2 saat, teorik) dersi 4. haftasında Hacı Bektaş-1 Veli şeklinde yer almaktadır. Yine 3.Sınıf 6.Yarıylda Günümüz İslam Dünyası Dini Akımlar (2 saat, teorik) ders içeriğinde 11 ve 12. Haftada Anadolu'da Alevilik Bektaşilik şeklinde doğrudan, 13 ve 14. Haftada "Türkiye'de Din Eğitimi ve İlahiyat Fakülteleri ve Mezhepler Üstü Yaklaşım” şeklinde verilen içeriğin kaynakları arasında Bektaşilik ile ilgili kaynakların yer aldığı görülmektedir. 4. Sınıf 8. Yarıyıl seçmeli dersleri arasında ise doğrudan Alevilik-Bektaşilik (2 saat, teorik) adıyla bir ders yer almaktadır. Dersin içeriği incelendiğinde Bektaşilik'in tarihsel süreci, düşünce yapısı, farklı coğrafyalardaki durumu gibi konuların detaylı bir şekilde ele alınmasının planlandığ1 görülmektedir ("Müfredat Dersleri”, 13 Kasım 2021).

Akdeniz Üniversitesi İlahiyat Fakültesi programında, Hacı Bektaş Veli’nin yeri incelendiğinde öğrencilerin, ilk olarak 2.Sınıf 4. Yarıyılda yer alan İslami Türk Edebiyatı dersinde ikinci olarak da 3. Sınıf 6. Yarıyılda Tasavvuf II dersinde Hacı Bektaş Veli ile karşılaşmaları mümkündür. Bu derslerin zorunlu olduğu düşünüldügünde Akdeniz Üniversitesi İlahiyat Fakültesi 4. Sınıf öğrencileri ve mezunlarının Hacı Bektaş Veli ile en az iki derste karşılaşması beklenmektedir. Bunun dışında ilgi alanları gibi etkenler ile seçeceği seçmeli derslerde de detaylı bir şekilde Hacı Bektaş Veli ile ilgili bilgi alma ve kendi zihin dünyasını inşa etme imkanı bulmasının mümkün olduğu görülmektedir. $\mathrm{Bu}$ değerlendirmelerin öğretim üyeleri tarafindan oluşturulan ve fakülte tarafindan internet sayfasında paylaşılan içeriğe ("Müfredat Dersleri”, 13 Kasım 2021) göre yapıldığını belirtmek yerinde olacaktır. Özellikle seçmeli derslerin açılması konusunda fakülte yönetiminin tercihlerinin de önemli olduğu dikkate alınmalıdır. Ayrıca, bu ders içeriklerinin uygulanma durumunun yanı sıra farklı derslerde, ödevlerde veya örtük program çerçevesinde fakülte 
içerisindeki çeşitli etkinlik ve ders dışı faaliyetlerde de öğrencilerin Hacı Bektaş Veli ile karşılaşması mümkündür.

\section{2. İlahiyat Fakültesi Öğrencilerinin Hacı Bektaş Veli ile İlgili Bilgi, Alg1 ve Karşılaşma Alanları}

Bu bölümde katılımcıların Hacı Bektaş Veli ile ilgili bilgi, alg1 ve karşılaşma alanlarına ilişkin sorulara verdiği cevaplara yer verilmiştir.

\section{Katılımcıların Hacı Bektaş Veli Hakkındaki Bilgi Düzeyi}

Hacı Bektaş Veli hakkındaki bilgi düzeylerinin sorulduğu soruya, katılımcılardan 80’i (\% 42,1) sadece adını duydum, 41'i (\% 21,6) hayatını biliyorum, 22'si (\% 11,6) eser/lerinin adını biliyorum, 36's1 (\% 18,9) hakkında yazılan metinleri okudum, 4'ü (\% 2,1) en az bir eserini okudum cevabını verirken, 7 katılımcı $(\% 3,7)$ ise kendisi ile ilgili hiçbir şey bilmiyorum şeklinde cevap vermiştir. Hacı Bektaş Veli hakkında herhangi bir bilgiye sahip olmadığını belirtenlerin (7 kişi) sinıflara göre dağılımı ise 4'ü 2.sınıf, 2'si 3. Sınıf, 1’i 1. Sınıf şeklindedir. Bu 7 kişi Hacı Bektaş Veli hakkında herhangi bir bilgi sahibi olmadığ için diğer sorular sorulmamış ve çalışmanın bu aşamasından sonrasına dahil edilmemiştir.

\section{Hacı Bektaş Veli ile İlgili Bilgi Kaynağı}

Hacı Bektaş Veli ile ilgili çeşitli düzeylerde bilgi sahibi olduğunu belirten katılımcılara bilgilerinin kaynağı sorulduğunda, katılımcıların 82'si $(\% 43,2)$ Lise derslerim ve/ya lise ders kitaplarım, 46's1 (\%24,2) Fakülte derslerim ve/ya ders kitaplarım, 28' $\mathrm{i}$ ise $(\% 14,7)$ Sosyal medya, 27'i ise $(\% 14,2) \mathrm{Tv}$, film, dizi, belgesel şeklinde cevap vermiştir. Buradan hareketle katılımcıların büyük çoğunluğunun (128 kişi/\%67,4) Hac1 Bektaş Veli hakkındaki bilgilerinin kaynağının okul merkezli olduğu söylenebilir. Bu durum katılımcıların Hacı Bektaş Veli hakkında bilimsel kaynaklara dayalı bilgileri öğrendikleri şeklinde yorumlanabilir.

Literatürdeki çalışmalara bakıldığında ise bilgi kaynaklarının benzer olduğu anlaşılmaktadır. Üniversite öğrencileri örnekleminde gerçekleştirilen çalışmada, Ahi Evran Üniversitesi öğrencileri, Hac1 Bektaş Veli ile ilgili bilgilerinin kaynağı olarak ilk sırada kitapları (\%21) söylemiştir. Diğer bilgi kaynakları ise sırasıyla hocaları $(\% 20,7)$ ve arkadaşları $(\% 13,1)$ şeklindedir. Nevşehir Hacı Bektaş Veli Üniversitesi öğrencileri ise Hacı Bektaş Veli ile ilgili en çok kitaplardan (\%22,7), sonra 
sırasıyla arkadaşlarından $(\% 17,6)$ ve hocalarından $(\% 11,4)$ bilgi edindiklerini belirtmişlerdir (Şahï, 2014, 181).

Toplum genelinden alınan örneklemden gelen cevaplara göre ise Hacı Bektaş Veli hakkında en çok bilgi alınan kaynağın televizyon $(\% 18.9)$ olduğu görülmektedir. Sirasıyla diğer bilgi kaynakları ise kitap $(\% 7,7)$, okul $(\% 6,6)$, gazete $(\% 2,4)$, dergi $(\% 2,3)$, aile $(\% 2,29$ ve internet $(\% 1,8)$ şeklindedir. Katılımcıların \% 52,2'si ise Hacı Bektaş Veli hakkında bu araçların tümünden bilgi edindiklerini belirtmiştir (Iş1k vd., 2010, 180).

Hacı Bektaş Veli hakkında bilgi edinilen kaynaklara ilişkin araştırmalara bir bütün olarak bakıldığında öğrencilerin, çoğunlukla okul merkezli bilgi kaynaklardan (ders, ders kitab1, öğretim üyesi), toplumun ise kitle iletişim araçları ve basın yoluyla bilgi edindiğini göstermektedir. Okul merkezli bilgi kaynaklarının öne çıkması, Hacı Bektaş Veli hakkında bilimsel ve doğru bilgiye erişime imkan tanıması yönüyle oldukça önemlidir. Diğer taraftan başta televizyon olmak üzere gazete, dergi vb. araçların teknolojik gelişmeler ve bilgiye erişim kaynaklarının değişmesinden etkilenmesinin muhtemel olduğu söylenebilir.

Tablo 1. Hacı Bektaş Veli'yi Öncelikle Nitelediği Sıfat

\begin{tabular}{|l|c|c|c|c|c|}
\hline \multicolumn{1}{|c|}{ Sıfat } & $\begin{array}{c}\text { Frekans } \\
(\mathbf{N})\end{array}$ & $\begin{array}{c}\text { Yüzde } \\
\mathbf{( \% )}\end{array}$ & Sifat & $\begin{array}{c}\text { Frekans } \\
\mathbf{( N )}\end{array}$ & $\begin{array}{c}\text { Yüzde } \\
\mathbf{( \% )}\end{array}$ \\
\hline Mutasavvıf & 28 & 15,3 & Pir Hünkar & 4 & 2,2 \\
\hline Alim & 21 & 11,5 & Tarikat & 4 & 2,2 \\
\hline Bektaşilik & 16 & 9,9 & Allah Dostu & 3 & 1,6 \\
\hline Hoca & 8 & 4,4 & Düşünür & 3 & 1,6 \\
\hline İslam Filozofu & 8 & 4,4 & Filozof & 3 & 1,6 \\
\hline Veli & 7 & 3,8 & Hoşgörülü & 3 & 1,6 \\
\hline Bektaşi & 6 & 3,3 & Tarikat Şeyhi & 3 & 1,6 \\
\hline Pir & 6 & 3,3 & Anadolu & 2 & 1,1 \\
\hline Şeyh & 6 & 3,3 & Derviş & 2 & 1,1 \\
\hline Tasavvuf & 6 & 3,3 & Horasan Ereni & 2 & 1,1 \\
\hline Din Adamı & 5 & 2,7 & Ilim & 2 & 1,1 \\
\hline Sufi & 5 & 2,7 & Diğer & 12 & 6,5 \\
\hline Alevilik & 4 & 2,2 & Fikrim Yok & 11 & 6,0 \\
\hline & Toplam & & 183 & 100,0 \\
\hline
\end{tabular}


Katılımcıların Hacı Bektaş Veli'yi öncelikle niteledikleri sıfatlara bakıldığında çoğunlukla tasavvuf ve Bektaşilik ekseninde olduğu görülmektedir. Katılımcıların Hacı Bektaş Veli'yi nitelemek için kullandıkları sıfatların gerçeklik ile uyumlu olduğu, bu durumun da katılımcıların büyük çoğunluğunun bilgi kaynağının okul (lise ve ilahiyat) olmasından kaynaklandığı söylenebilir. Ayrıca katılımcıların hiçbiri Hacı Bektaş Veli için olumsuz bir nitelemede bulunmamıştır. Katılımcılardan $11^{\prime} i(\% 6)$ ise fikrim yok şeklinde cevap vermiştir.

\section{İlahiyat Eğitimi Süresince Hacı Bektaş Veli'den Bahsedilme Durumu}

Katılımcıların, İlahiyat eğitimleri süresince Hacı Bektaş Veli'den bahsedilme durumuna ilişkin soruya verdikleri cevaplara bakıldığında, katılımciların 87'si (\%47,5) evet bahsedildi, 96's1 (\%52,5) hayır bahsedilmedi yanıtını vermiştir. Katılımcılardan İlahiyat eğitimi süresince Hacı Bektaş Veli'den bahsedildiğini belirtenlerin nerelerde Hacı Bektaş Veli ile karşılaştıklarını belirlemek için çalışmanın bu aşamasından sonra "hayır bahsedilmedi" cevabını veren 96 kişi çalışmanın bu aşamasından sonrasına dahil edilmemiştir.

\section{İlahiyat Eğitimi Süresince Hacı Bektaş Veli Hakkında En Çok Bilginin Nereden/Kimden Öğrenildiği}

İlahiyat eğitimleri süresince Hacı Bektaş Veli hakkında en çok bilgiyi nereden öğrendikleri sorusuna katılımcıların 58'i $(\% 66,7)$ derslerde edindiklerini, 9’u (\%10,3) ödev vb. araştırmalarda, 9’u (\%10,3) öğretim üyeleri ile sohbet vb. konuşmalarda, 8'i $(\% 9,2)$ vakıf vb. okul dişı faaliyetlerde, 3 'ü ise $(\% 3,4)$ sempozyum/konferans/seminerlerde şeklinde cevap vermiştir. Bu durum Hacı Bektaş Veli ile öğrencilerin çoğunlukla derslerde veya ilahiyat fakültesi ortamında karşılaştıkları şeklinde yorumlanabilir. Bu durum ise $\mathrm{Hac1}$ Bektaş Veli'nin sadece ilahiyat fakültesinin resmi programında değil örtük programında da yer aldığını göstermektedir. 


\section{Tablo 2 İlahiyat Eğitiminde Hacı Bektaş Veli'ye Yer Verilen Dersler (4. Sınıf Öğrencilerine Göre)}

\begin{tabular}{|c|c|c|}
\hline Dersler & Frekans (N) & Yüzde (\%) \\
\hline Tasavvuf vb. derste & 28 & 46,7 \\
\hline Mezhepler Tarihi vb. derste & 5 & 8,3 \\
\hline İslam Edebiyatı vb. derste & 3 & 5,0 \\
\hline $\begin{array}{l}\text { Tasavvuf vb. derste; İslam Edebiyatı } \\
\text { vb. derste }\end{array}$ & 3 & 5,0 \\
\hline $\begin{array}{l}\text { Tasavvuf vb. derste; Mezhepler Tarihi } \\
\text { vb. derste }\end{array}$ & 2 & 3,3 \\
\hline Din Eğitimi & 1 & 1,7 \\
\hline $\begin{array}{l}\text { İslam Edebiyat1 vb. derste; Din } \\
\text { Sosyolojisi vb. derste }\end{array}$ & 1 & 1,7 \\
\hline $\begin{array}{l}\text { Tasavvuf vb. derste; Din Sosyolojisi } \\
\text { vb. derste }\end{array}$ & 1 & 1,7 \\
\hline $\begin{array}{l}\text { Tasavvuf vb. derste; Mezhepler Tarihi } \\
\text { vb. derste }\end{array}$ & 1 & 1,7 \\
\hline $\begin{array}{l}\text { Tasavvuf vb. derste; Mezhepler Tarihi } \\
\text { vb. derste; İslam Edebiyatı vb. derste }\end{array}$ & 1 & 1,7 \\
\hline Türk Düşünce Tarihi & 1 & 1,7 \\
\hline Cevapsiz & 13 & 21,7 \\
\hline Toplam & 60 & 100,0 \\
\hline
\end{tabular}

Katılımcılar arasında en çok dersi alan ve ilahiyat eğitimini büyük oranda tamamlamış olanlar 4.sınıf öğrencileridir (60 kişi). Alt sınıflardaki öğrencilerin henüz almadığ derslerde Hacı Bektaş Veli’ye yer verilebilme ihtimali dikkate alınarak, Hacı Bektaş Veli'ye hangi derslerde yer verildiği sorusu 4. Sınıf öğrencilerine sorulmuștur. Katılımcıların birden fazla derste Hacı Bektaş Veli’ye yer verildiğine şahit olabileceği düşünülerek bu soruda katılımcıların birden fazla yanıt vermelerine imkan tanınmıştır. Verilen cevaplara bakıldığında, ilahiyat eğitimi süresince katılımcılar en çok Tasavvuf vb. derste, daha sonra ise Mezhepler Tarihi vb. derste ve İslam Edebiyatı vb. derste Hacı Bektaş Veli'ye yer verildiğini belirtmektedir. Birer öğrenci ise Din Eğitimi ve Türk Düşünce Tarihi derslerinde Hacı Bektaş Veli’ye yer verildiğini belirtmiştir. 4. Sınıfta okuduğunu belirten 13 katılımcı ise bu soruyu cevapsız bırakmıştır. 


\section{SONUÇ}

İlahiyat Fakültesi öğrencilerinin Hacı Bektaş Veli ile ilgili bilgi, alg1 ve karşılaşma alanlarının ele alındığı bu çalışma sonucunda katılımcıların büyük çoğunluğunun $(\% 96,3)$ Hac1 Bektaş Veli hakkında çeşitli düzeylerde bilgi sahibi olduğu tespit edilmiştir. Katılımcıların bilgilerinin kaynağ1 ise büyük oranda $(\% 67,4)$ okul merkezlidir. Diğer bilgi kaynaklan1 ise kitle iletişim araçları merkezlidir. Bu gruptaki bilgi kaynakları önceki yıllarda yapılan benzer araştırmalarla bir farklılaşmaya işaret etmektedir. Önceki yıllardaki araştırmalarda yer almayan bir bilgi kaynağı olarak sosyal medya öne çıkmakta ve televizyon, gazete, dergi gibi araçlar artık birer bilgi kaynağ1 olarak belirtilmemektedir. Bu bulgular teknolojik gelişmelerle birlikte bilgi kaynaklarında da bir dönüşüme işaret etmektedir.

Hacı Bektaş Veli ile ilgili algılar incelendiğinde ise, katılımcıların mutasavvıf, alim, Bektaşilik gibi çoğunlukla tasavvuf ile ilgili sıfatları kullandıkları anlaşılmaktadır. Literatürdeki çalışmalarda da benzer sıfatların kullanıldığ1 düşünüldüğünde ilahiyat fakültesi öğrencilerinin Hacı Bektaş Veli algılarının olumlu olduğu görülmektedir. Bu durumun da bilgi kaynaklarının okul merkezli olmasından dolayı bilimsel bir kaynağa dayanmasından kaynaklandığı söylenebilir.

Katılımcıların \% 47,5’i İlahiyat eğitimi süresince Hacı Bektaş Veli'den bahsedildiğini belirtmiştir. Farklı sınıf düzeyinden katılımcıların yer aldığı örneklemden elde edilen bu bulgunun, müfredat incelemesinde Hac1 Bektaş Veli ile ilgili derslerden ilkinin 4. Yarryılda yer almasından kaynaklandığ1 söylenebilir. Zira katılımcıların ilahiyat eğitiminde Hacı Bektaş Veli ile karşılaşma alanları, verilen yanıtlara göre çoğunlukla ders merkezlidir (\%66,7 derslerde, \%10,3 ödev vb. araştırmalarda). Bu noktada katılımcıların ilahiyat eğitimi süresince hangi derslerde Hac1 Bektaş Veli ile karşılaştıklarını belirlemek için sorulan soruya, eğitimini büyük oranda tamamlamış olan 4.sınıf öğrencilerinin verdiği cevaplar analiz edilmiştir. Bu öğrencilerin cevaplarına göre Hacı Bektaş Veli'ye Tasavvuf vb., Mezhepler Tarihi vb. ve İslam Edebiyatı vb. derslerde yer verilmektedir. Ders içerikleri incelendiğinde elde edilen bulgular ile sahadan elde edilen bulgular arasında bir uyum olduğu görülmektedir. Ders içeriklerinde en çok Tasavvuf vb. derslerde yer alan Hacı Bektaş Veli, öğrenciler tarafindan da en çok bu dersler aracıllŭ̆yla öğrenilmektedir. Hacı Bektaş Veli ile ilgili algıyı belirlemek için sorulan 
Hac1 Bektaş Veli'yi öncelikle niteleyen sıfat sorusuna çoğunlukla tasavvufla ilgili kavramların cevap olarak yazılmasının, bilgi kaynağı dersin tasavvuf vb. dersler olmasından kaynaklandığı anlaşılmaktadır.

Sonuç olarak, İlahiyat öğrencilerinin Hacı Bektaş Veli hakkında büyük oranda bilgi sahibi oldukları, bu bilginin de çoğunlukla kitaplardan edinildiği anlaşılmaktadır. Katılımcıların Hacı Bektaş Veli ile çoğunlukla derslerde karşılaştıklarını ifade etmelerinden hareketle de İlahiyat eğitiminde Hacı Bektaş Veli’ye yer verildiği anlaşılmaktadır. Ancak çoğunlukla tasavvuf vb. derslerde yer alması öğrencilerin Hacı Bektaş Veli'den sınırlı bir alanda haberdar oldukları farklı yön ve alanlarda yeterince istifade edemedikleri şeklinde yorumlanabilir. 


\section{KAYNAKÇA}

Creswell, John W. - Plano Clark, Vicki L. Karma Yöntem Arastırmalar Tasarmı ve Yürïtülmesi. Ankara: Anı Yayıncil1k, 2. Basım, 2015.

Çifci, Selcen. "Bir Grup Yükseköğretim Öğrencisinin Hacı Bektaş Veli'yi Tanıma Düzeyi ve Bektaşilik Hakkındaki Tutumları". Türk Kültürü ve Hace Bektas Veli Arastrma Dergisi 57 (2011). https://hbvdergisi.hacibayram.edu.tr/index.php/TKHBVD/article/ view/1240

Işık, Metin vd. "Türk Toplumunda Hac1 Bektaş Velî Alg1sı Üzerine Bir Çalışma”. Türk Kültürü ve Hacı Bektaș Velî Araștırma Dergisi 55 (2010). https://hbvdergisi.hacibayram.edu.tr/index.php/TKHBVD/article/ view/1178

Okur, Alpaslan. "Hacı Bektaş Velî ve İlgili Kavramların Tanınabilirlik/Algısı Üzerine Bir Araştırma ve Öğretim Programlarındaki (Meb) Durumu". Türk Kültürü ve Hact Bektas Velî Arastırma Dergisi 64 (2012). https://hbvdergisi.hacibayram.edu.tr/index.php/TKHBVD/article/ view/126

Öztaşkın, Özlem Bektaş. "Öğretim Programları ve Ders Kitaplarında Hacı Bektaş Velî ve Bektaşilik". Türk Kültürü ve Hacı Bektaș Velì Araştırma Dergisi 61 (2012). https://hbvdergisi.hacibayram.edu.tr/index.php/TKHBVD/article/ view/194

Şahin, Ayfer. "Nevşehir Hacı Bektaş Veli ve Ahi Evran Üniversitesi Öğrencilerinin Hacı Bektaş Veli ve Ahi Evran-1 Veli ile Bektaşilik ve Ahilik Algiları". Türk Kültürü ve Hacı Bektass Velì Araștırma Dergisi 71 (2014), 171-196.

Tanyıldızı, Nural İmik. "Türk Kültürünün Gençlere Tanıtımında Medyanın Rolü: Hacı Bektaş Velî, Mevlana ve Yunus Emre Üzerine Bir Araştırma". Türk Kültürü ve Hacı Bektas Velî Araștırma Dergisi 59 (2011).

https://hbvdergisi.hacibayram.edu.tr/index.php/TKHBVD/article/ view $/ 477$

Yazıcı, Hikmet. "Öğretmen Adaylarının Hacı Bektaş Veli ve Bektaşilikle İlgili Temel Bilgi ve Tutum Düzeyleri”. Türk Kültürü ve Hacı Bektass Veli Arasstrma Dergisi 72 (2014), 109-123.

"Müfredat Dersleri”. Erişim $13 \quad$ Kasım 2021. https://obs.akdeniz.edu.tr/oibs/ogrsis/mufredat_dersleri.aspx 